\title{
HUBUNGAN TINGKAT PENGETAHUAN ORANGTUA TENTANG STIMULASI VERBAL DENGAN PERKEMBANGAN BAHASA PADA ANAK USIA DINI DI TK YAYASAN BHAKTI SIWI DESA SORAN KABUPATEN KLATEN
}

\author{
Rahayu Setyaningsih', Neri Anggasari ${ }^{2}$
}

\begin{abstract}
Background : children who experience language disorders in preschool $40 \%$ to $60 \%$ will have learning difficulties in writing and academic subjects. Information from one of the parents of students in kindergarten Yayasan Bhakti Siwi Soran village during the 2016/2017 school year in which students in the kindergarten were 32 students, 9 of them have not been able to use words that are obvious in everyday communication, some parents provide stimulation to train their children to talk, some parents motivate for daring to express their opinions, but there are also parents not know how to stimulate children who have a language disorder.

Purpose of the study: to determine the relationship of the level of parental knowledge about verbal stimulation with language development in early children at the TK Yayasan Bhakti Siwi Soran village.

Methods : the research design correlation with cross sectional approach. Subject were 32 student with mother. Data obtained by questionaire to determine level of parental knowledge with language development. Data analyzed with Chi Square test $p=0.05$.

Results : based on the test results of the bivariate analysis using Chi-Square with $\alpha=$ $5 \%(0.05)$ was obtained $p<0.001$ to $p<0.05$, which means the hypothesis is accepted. Conclusion : there is the correlation between parental knowledge about verbal stimulation with language development in children.
\end{abstract}

Keywords: Knowledge, Verbal Stimulation, Language Development

\section{PENDAHULUAN}

Perkembangan anak merupakan proses kontinyu yang terjadi mulai sejak konsepsi sampai dewasa. Apakah perkembangan anak berjalan sesuai dengan potensi genetiknya atau tidak, tergantung pada lingkungan di sekitar anak dalam memanfaatkan masa kritis tersebut. Apakah lingkungan tersebut menunjang atau menghambat perkembangan anak? Bagaimana dengan maturasi otak anak pada saat itu? Salah satu faktor lingkungan yang dapat mengoptimalkan perkembangan anak adalah stimulasi bahasa. Stimulasi bahasa adalah rangsangan perkembangan bahasa pada anak yang datang dari lingkungan luar. Stimulasi merupakan salah satu aspek kebutuhan dasar anak (Soetjiningsih dan Ranuh, ed., 2014).

Stimulasi suara atau verbal ternyata sangat manjur bagi perkembangan kecerdasan, terutama dalam bidang kecerdasan linguistik atau bahasa, karena dapat meningkatkan kualitas dan kuantitas vokal secara tajam. Bila orang tua menanggapi celotehan anak secara responsif verbal, anak akan merespon kembali melalui vokalisasi yang lebih berkualitas dan semakin sering dipraktikkan. Pembelajaran seperti ini akan berpengaruh pada kefasihan anak dalam praktik kemampuan berbicara atau berbahasa (Tembong, 2006).

Berdasarkan data kunjungan pasien di ruang poli tumbuh kembang $R S$ Dr. Kariadi Semarang selama bulan Juni sampai November 2004 dimana 100 dari 250 jumlah 
kunjungan melakukan pemeriksaan Denver Developmental Screening Test (DDST) dan dari 100 ditemukan gangguan bahasa sebanyak $75 \%$, kasus lain antara lain malnutrisi, retardasi mental dan ADHD (Attention Deficit Hiperactivity Disorder). Hartanto (2011) sebagaimana dikutip oleh Handayani, Samiasih dan Mariyam, (2013), menerangkan selama tahun 2007 di poliklinik tumbuh kembang anak RS Dr. Kariadi Semarang didapatkan $22,9 \%$ dari 436 kunjungan baru datang dengan keluhan terlambat bicara, 13 $(2,98 \%)$ di antaranya didapatkan gangguan perkembangan bahasa.

Menurut Syaodin (2001) dalam Susanto (2014), bahwa aspek bahasa berkembang dimulai dengan peniruan bunyi. Perkembangan selanjutnya berhubungan dengan perkembangan intelektual dan sosial. Bahasa merupakan alat untuk berfikir. Berfikir merupakan suatu proses memahami dan melihat hubungan. Proses ini tidak mungkin dapat berlangsung dengan baik tanpa alat bantu, yaitu bahasa. Bahasa juga merupakan alat komunikasi dengan orang lain dan kemudian berlangsung dalam suatu interaksi sosial. Bahasa adalah alat untuk berfikir, mengekspresikan diri dalam berkomunikasi. Keterampilan bahasa juga penting dalam rangka pembentukan konsep, informasi, dan pemecahan masalah. Melalui bahasa pula kita dapat memahami komunikasi pikiran dan perasaan.

Anak yang mengalami kelainan bahasa pada prasekolah $40 \%$ hingga $60 \%$ akan mengalami kesulitan belajar dalam bahasa tulisan dan mata pelajaran akademik. Sidiarto (2002) dalam Handayani, Samiasih dan Mariyam (2013), menyebutkan bahwa anak yang dirujuk dengan kesulitan belajar spesifik, lebih dari $60 \%$ mempunyai keterlambatan bicara. Rice (2007) dalam Handayani,
Samiasih dan Mariyam (2013), menyebutkan, apabila disfasia perkembangan tidak diatasi secara dini, $40 \%$ sampai dengan $75 \%$ anak akan mengalami kesulitan untuk membaca.

Perkembangan bahasa pada anak terdiri atas komunikasi aktif dan pasif yang perlu dikembangkan secara bertahap. Anak perlu dilatih untuk mau dan mampu berkomunikasi aktif (berbicara, mengucapkan kalimat-kalimat, menyanyi dan bentuk ungkapan lisan lainnya), dan berkomunikasi pasif (anak mengerti orang lain). Pada balita, kemampuan berpikir mula-mula berkembang melalui kelima inderanya, misalnya melihat warna, mendengar suara, dan mengenal rasa. Daya pikir dan pengertian mula-mula terbatas pada apa yang nyata (konkret), yang dapat dilihat dan dipegang atau dimainkan. Melalui bermain serta latihan yang diberikan orangtua atau orang lain, setahap demi setahap anak akan mengenal dan mengerti lingkungannya dan memiliki kemampuan merencanakan persoalan (Susanto, 2014). Diperlukan pengetahuan yang cukup pada orangtua tentang cara menstimulasi perkembangan bahasa pada anak agar bisa mengajari bagaimana berkomunikasi dan mengajari anak berbicara. Menurut Wawan dan Dewi (2011), pengetahuan (knowledge) adalah hasil dari "tahu" dan ini terjadi setelah orang melakukan penginderaan terhadap suatu objek tertentu. Sebagian besar pengetahuan manusia diperoleh melalui mata dan telinga. Pengetahuan atau kognitif merupakan domain yang sangat penting dalam membentuk tindakan seseorang (overt behavior).

Informasi dari salah satu orang tua siswa di TK Yayasan Bhakti Siwi Desa Soran selama tahun ajaran 2016/2017 dimana siswa di TK 
tersebut sebanyak 32 siswa 9 diantaranya belum dapat menggunakan kata-kata yang jelas dalam komunikasi sehari-hari, beberapa orang tua memberikan stimulasi untuk melatih anaknya dengan cara mengajak bicara, sedangkan beberapa orang tua dengan cara melatih anak dengan memotivasi untuk berani mengungkapkan pendapatnya, namun ada juga orangtua yang belum tahu bagaimana cara menstimulasi anak yang mengalami kendala bahasa.

Berdasarkan paparan di atas, peneliti tertarik untuk melakukan penelitian dengan judul "Hubungan Tingkat Pengetahuan lbu tentang Stimulasi Verbal dengan Perkembangan Bahasa pada Anak Usia Dini di TK Yayasan Bhakti Siwi Desa Soran".

\section{TUJUAN PENELITIAN}

Untuk mengetahui hubungan tingkat pengetahuan orangtua tentang stimulasi verbal dengan perkembangan bahasa pada anak.

\section{DESAIN PENELITIAN}

Penelitian ini merupakan penelitian analitik dengan desain korelasi dan pendekatan cross sectional untuk mengetahui hubungan pengetahuan orangtua tentang stimulasi verbal sebagai variabel bebas (independent variabel) dengan perkembangan bahasa pada anak usia dini sebagai variabel terikat (dependent variable).

\section{POPULASI, SAMPEL, DAN TEHNIK SAMPLING}

Populasi pada penelitian ini adalah seluruh siswa di TK Yayasan Bhakti Siwi Desa Soran di tahun ajaran 2016/2017 yang berjumlah 32 siswa beserta orangtuanya. Dalam penelitian ini peneliti menggunakan semua populasi yang ada sebagai sampel. Teknik sampling yang digunakan adalah teknik total sampling (sampling jenuh).

\section{HASIL PENELITIAN}

Karakteristik responden orangtua diketahui berdasarkan umur, agama, tingkat pendidikan dan pekerjaan, sedangkan karakteristik balita berdasarkan jenis kelamin dan umur sebagai berikut:

Tabel 1. Karakteristik Responden

\begin{tabular}{lccc}
\hline Karakteristik & Kategori & $\mathrm{f}$ & $\%$ \\
\hline Umur Orang & $20-34$ & 16 & 50.0 \\
Tua (tahun) & $35-44$ & 15 & 46.9 \\
& $45-54$ & 1 & 3.1 \\
Pendidikan & Dasar & 8 & 25.0 \\
& $\begin{array}{l}\text { Mene- } \\
\text { ngah }\end{array}$ & 21 & 65.6 \\
& Tinggi & 3 & 9.4 \\
& Tdk & 25 & 78.1 \\
Pekerjaan & Swasta & 5 & 15.6 \\
& Guru & 2 & 6.3 \\
& Ya & 25 & 78.1 \\
Informasi & Tidak & 7 & 21.9 \\
& & & \\
Jml Anak & $1-2$ & 26 & 81.3 \\
& $>2$ & 6 & 18.7 \\
Jenis & Laki-laki & 21 & 65.6 \\
Kelamin & Perem- & 11 & 34.4 \\
Anak & puan & & \\
Usia Anak & 3 & 3 & 9.4 \\
(tahun) & 4 & 14 & 43.8 \\
& 5 & 15 & 46.8 \\
\hline & & &
\end{tabular}

Jumlah responden terbanyak adalah orang tua usia $20-34$ tahun yaitu 16 orang (50.0\%). Pendidikan terbanyak menengah yaitu 21 orang $(65.6 \%)$. Pekerjaan yang terbanyak adalah ibu rumah tangga (tidak bekerja) yaitu 25 orang (78.1\%). Informasi tentang stimulasi verbal paling banyak mengaku pernah mendapatkan yaitu 25 orang (78.1\%). Jumlah anak paling banyak adalah mempunyai 1-2 anak yaitu 26 orang $(81.3 \%)$. Jenis kelamin 
balita 21 orang $(65.6 \%)$ berjenis kelamin laki-laki dan 11 balita (34.4 $\%$ berjenis kelamin perempuan. Untuk usia balita yang terbanyak adalah usia 5 tahun yaitu 15 orang $(46.8 \%)$.

Tabel 2

\begin{tabular}{lcc}
\hline Pengetahuan & $\mathrm{f}$ & $\%$ \\
\hline Tinggi & 22 & 68.7 \\
Sedang & 8 & 25.0 \\
Rendah & 2 & 6.3 \\
\hline Jumlah & 32 & 100
\end{tabular}

\section{Distribusi Frekuensi Variabel Pengetahuan}

Dari tabel di atas dapat diketahui bahwa sebagian besar responden berada pada tingkat pengetahuan tinggi yaitu 22 orang (68.7\%), sedangkan 2 orang (6.3\%) berada pada tingkat pengetahuan rendah.

Tabel 3.

Distribusi Frekuensi Variabel Bahasa

\begin{tabular}{lcc}
\hline \multicolumn{1}{c}{ Bahasa } & $\mathrm{f}$ & $\%$ \\
\hline Optimal & 22 & 68.7 \\
Kurang optimal & 8 & 25.0 \\
Tidak optimal & 2 & 6.3 \\
\hline \multicolumn{1}{c}{ Jumlah } & 32 & 100 \\
\hline
\end{tabular}

Dari tabel di atas dapat diketahui bahwa sebagian besar responden mengalami perkembangan bahasa yang optimal sejumlah 22 orang $(68.7 \%)$, sedangkan 2 orang $(6.3 \%)$ perkembangan bahasanya tidak optimal.
Tabel 4.

Tabulasi Silang Hubungan Tingkat Pengetahuan Tentang Stimulasi Verbal Dengan Perkembangan Bahasa

\begin{tabular}{ccccc}
\hline \multirow{2}{*}{$\begin{array}{c}\text { Penge- } \\
\text { tahuan }\end{array}$} & \multicolumn{3}{c}{$\begin{array}{c}\text { Perkembangan } \\
\text { Bahasa }\end{array}$} & Jml \\
\cline { 2 - 5 } & $\begin{array}{c}\text { Opti } \\
\text { Mal }\end{array}$ & Krg & Tdk \\
\hline Tinggi & 21 & 1 & 0 & 22 \\
Sedang & 1 & 7 & 0 & 8 \\
Rendah & 0 & 0 & 2 & 2 \\
\hline$p$ & \multicolumn{4}{c}{0,001} \\
\hline
\end{tabular}

Berdasarkan tabel di atas dapat dilihat bahwa

1. Terdapat responden yang mempunyai tingkat pengetahuan tinggi yaitu 22 orang, 21 diantaranya perkembangan bahasa anaknya optimal dan 1 orang perkembangan bahasa anaknya kurang optimal.

2. Terdapat responden yang mempunyai tingkat pengetahuan sedang yaitu 8 orang, 1 diantaranya perkembangan bahasa anaknya optimal dan 7 orang perkembangan bahasa anaknya kurang optimal.

3. Terdapat responden yang mempunyai tingkat pendidikan rendah yaitu 2 orang, dan perkembangan bahasa anak semuanya tidak optimal.

Berdasarkan hasil uji statistik bivariat dengan menggunakan $\mathrm{Chi}$ Square dengan $\alpha=5 \% \quad(0,05)$ diperoleh $p$ sebesar $<0,001$ sehingga $p<0,05$, yang berarti hipotesa diterima maka dapat ditarik kesimpulan bahwa ada hubungan tingkat pengetahuan tentang stimulasi verbal dengan perkembangan bahasa pada anak usia dini di TK Yayasan Bhakti Siwi Desa Soran Klaten. 


\section{PEMBAHASAN}

1. Tingkat Pengetahuan Orangtua Tentang Stimulasi Verbal

Dari tabel 2 dapat diketahui bahwa sebagian besar responden berada pada tingkat pengetahuan tinggi yaitu 22 orang $(68.7 \%)$, sedangkan 8 orang $(25.0 \%)$ berada pada tingkat pengetahuan sedang dan 2 orang (6.3\%) dengan tingkat pengetahuan rendah. Menurut Wawan dan Dewi (2011), faktorfaktor yang mempengaruhi tingkat pengetahuan salah satunya adalah pendidikan. Pendidikan diperlukan untuk mendapat informasi misalnya halhal yang menunjang kesehatan sehingga dapat meningkatkan kualitas hidup. Dari tingkat pendidikan diperoleh informasi bahwa jumlah responden terbanyak adalah pendidikan tingkat menengah yaitu 21 orang (65,6 \%). Dengan pendidikan tingkat menengah dimungkinkan responden memperoleh informasi lebih banyak daripada responden dengan pendidikan yang lebih rendah. Selain faktor pendidikan adalah pekerjaan, yaitu kegiatan yang harus dilakukan terutama untuk menunjang kehidupannya dan kehidupan keluarga, tetapi lebih banyak merupakan kegiatan yang menyita waktu. Responden dalam penelitian ini sebagian besar adalah ibu yang tidak bekerja, yaitu 25 orang (78.1\%), dan responden paling sedikit bekerja sebagai guru yaitu sebanyak 2 orang (6.3\%), ibu yang tidak bekerja lebih banyak waktu untuk mendapatkan informasi baik melalui media massa (televisi, majalah atau koran) selain itu pekerjaan responden yang lain adalah swasta 5 orang (15.6\%), dari pekerjaan tersebut menunjukkan bahwa responden banyak berinteraksi dengan orang lain sehingga memberikan pengalaman dan pengetahuan kepada responden secara langsung.

Faktor selanjutnya adalah usia, yaitu umur individu yang terhitung mulai saat dilahirkan sampai berulang tahun. Semakin cukup umur, tingkat kematangan dan kekuatan seseorang akan lebih matang dalam berfikir dan bekerja. Dari segi kepercayaan masyarakat seseorang yang lebih dewasa dipercaya dari orang yang belum tinggi kedewasaannya. Hal ini berkaitan dengan pengalaman dan kematangan jiwa. Berdasarkan usia diperoleh informasi bahwa jumlah responden terbanyak adalah usia 20 - 34 tahun yaitu 16 orang $(50.0 \%)$, dan usia 35 44 tahun sejumlah 15 orang (46.9 $\%$ ), usia tersebut termasuk dalam usia produktif dimana daya tangkap dan pola pikir berkembang optimal sehingga responden mampu mencari informasi yang dibutuhkan dengan baik.

2. Perkembangan Bahasa

Berdasarkan tabel 3 dapat dilihat bahwa terdapat anak dengan perkembangan bahasa yang optimal yaitu 22 orang (68.7\%), kurang optimal sejumlah 8 orang $(25.0 \%)$ dan 2 orang $(6.3 \%)$ dengan perkembangan bahasa yang tidak optimal. Menurut Zubaidah (2014) faktor yang mempengaruhi perkembangan bahasa dan berbicara meliputi: kondisi jasmani dan kemampuan motorik, kesehatan umum, kecerdasan, sikap lingkungan, faktor sosial ekonomi, jenis kelamin, kedwibahasaan dan neurologi. Dari faktor kondisi jasmani dan kemampuan motorik, menurut Tarmansyah (1996) sebagaimana yang dikutip oleh Zubaedah (2014) bahwa seorang anak yang mempunyai 
fisik sehat, tentunya mempunyai kemampuan gerak yang lincah dan penuh energi. Anak yang demikian akan selalu bergairah dan lincah dalam bergerak dan selalu ingin tahu benda-benda yang ada di sekitarnya. Bendabenda tersebut dapat diasosiasikan anak menjadi sebuah pengertian. Untuk selanjutnya pengertian tersebut dilahirkan dalam bentuk bahasa. Konsep bahasa pada anak yang kondisi fisiknya normal tentunya berbeda dengan anak yang mempunyai kondisi fisik terganggu. Anak yang mempunyai kondisi fisik normal akan mempunyai konsep bahasa yang lebih lengkap jika dibandingkan dengan anak yang kondisi fisiknya terganggu. Pada saat penelitian ini dilaksanakan semua anak dalam kondisi fisik yang sehat dan normal sehingga sebagian besar anak (68.7\%) perkembangan bahasanya optimal. Faktor yang lain adalah jenis kelamin, menurut Zubaedah (2014) bahwa anak laki-laki dan anak perempuan perkembangan bahasanya relatif lebih cepat anak perempuan. Oleh karena itu perbendaharaan bahasanya lebih banyak dimiliki oleh anak perempuan. Demikian juga dalam hal ucapan, anak perempuan lebih jelas artikulasinya. Perbedaan antara anak laki-laki dan perempuan tersebut akan berlangsung sampai menginjak usia sekolah. Sejalan dengan hal tersebut, berdasarkan tabel 1 penelitian ini didominasi anak dengan jenis kelamin perempuan yaitu sejumlah 21 anak (65.6\%), sehingga dimungkinkan hasil penelitian yang menunjukkan bahwa anak dengan perkembangan bahasa yang optimal sebagian besar berjenis kelamin perempuan.
3. Hubungan Tingkat Pengetahuan Orangtua Tentang Stimulasi Verbal Dengan Perkembangan Bahasa

Berdasarkan tabel 4 yang mempunyai tingkat pengetahuan tinggi yaitu 22 orang, 21 diantaranya

perkembangan bahasa anaknya optimal dan 1 orang perkembangan bahasa anaknya kurang optimal, terdapat responden yang mempunyai tingkat pengetahuan sedang yaitu 8 orang, 1 diantaranya perkembangan bahasa anaknya optimal dan 7 orang perkembangan bahasa anaknya kurang optimal, terdapat responden yang mempunyai tingkat pendidikan rendah yaitu 2 orang, dan perkembangan bahasa anak semuanya tidak optimal.

Berdasarkan hasil uji statistik bivariat dengan menggunakan Chi Square dengan $\alpha=5 \%(0.05)$ diperoleh $p$ sebesar $<0.001$ sehingga $p<0.05$, yang berarti hipotesa diterima maka dapat ditarik kesimpulan bahwa ada hubungan tingkat pengetahuan tentang stimulasi verbal dengan perkembangan bahasa pada anak usia dini di TK Yayasan Bhakti Siwi Desa Soran Klaten. Jadi jelaslah dengan penelitian ini bahwa tingkat pengetahuan orangtua sangat berperan dalam perkembangan bahasa anak.

Menurut Budiman dan Riyanto (2013), faktor-faktor yang mempengaruhi pengetahuan antara lain : selain pendidikan dan usia ada pula pengalaman. Pengalaman sebagai sumber pengetahuan adalah suatu cara untuk memperoleh kebenaran pengetahuan dengan cara mengulang kembali pengetahuan yang diperoleh dalam memecahkan masalah yang dihadapi masa lalu. Dari tabel 1 
di atas diperoleh informasi bahwa jumlah responden yang mempunyai anak 1-2 orang adalah 26 orang (81\%), dan responden yang mempunyai anak lebih dari 2 sebanyak 6 orang (19\%). lbu yang mempunyai anak kedua atau lebih dimungkinkan lebih mempunyai pengalaman dalam memberikan stimulasi verbal kepada anaknya dan juga ibu yang mempunyai anak kurang dari 2 orang dimungkinkan memberikan perhatian yang lebih banyak kepada anaknya daripada ibu yang mempunyai anak lebih dari 2. Selain itu dari tabel 1 di atas responden yang mengaku mendapatkan informasi tentang stimulasi verbal pada anak sebelumnya adalah 25 orang $(78 \%)$, dan responden yang mengaku belum pernah mendapatkan informasi sebanyak 7 orang (22\%). Dari informasi tersebut bisa dijelaskan bahwa orangtua yang belum pernah mendapatkan informasi tentang stimulasi verbal kemungkinan besar juga tidak paham bagaimana cara memberikan stimulasi bahasa pada anaknya sehingga diantara anak-anak tersebut didapatkan ada 7 orang anak dengan tingkat pengetahuan orangtua sedang yang perkembangan bahasanya tidak optimal, demikian juga dengan 2 anak dengan tingkat pengetahuan orangtua rendah dan keduanya mengalami perkembangan bahasa yang tidak optimal.

Penelitian ini sejalan dengan penelitian yang dilakukan oleh Handayani, Samiasih dan Mariyam (2012), untuk membuktikan adanya hubungan tingkat pengetahuan orang tua tentang stimulasi verbal dengan perkembangan bahasa pada anak prasekolah dengan hasil ada hubungan bermakna tingkat pengetahuan orang tua tentang stimulasi verbal dengan perkembangan bahasa anak prasekolah. Sesuai juga dengan penelitian yang dilakukan oleh Wati (2016), dengan hasil penelitian menunjukkan bahwa $51.8 \%$ ibu melakukan stimulasi cukup dan $56.63 \%$ anak memiliki perkembangan sesuai sehingga hasil uji korelasi Spearman Rho didapatkan nilai $\mathrm{p}$ value 0,001 $(p<0,05)$ yang berarti terdapat hubungan antara stimulasi perkembangan dengan perkembangan anak usia 0-5 tahun. Dengan demikian pemberian stimulasi sesuai tahapan usia disarankan untuk dilakukan secara rutin agar anak mencapai perkembangan yang optimal.

\section{KESIMPULAN}

Dari hasil penelitian diperoleh kesimpulan sebagai berikut: didapatkan hasil frekuensi paling banyak pada tingkat pengetahuan tinggi yaitu 22 responden (68.7\%), dan frekuensi tingkat pendidikan rendah yaitu 2 responden (6.3\%), frekuensi paling banyak pada perkembangan bahasa optimal yaitu 22 anak (68.7\%), dan tidak optimal yaitu 2 anak (6.3\%), hasil uji analisa bivariat menggunakan Chi Square dengan $\alpha=5 \%(0,05)$ diperoleh $p<$ 0,001 sehingga $p<0,05$ maka ada hubungan tingkat pengetahuan orangtua tentang stimulasi verbal dengan perkembangan bahasa pada anak usia dini di TK Yayasan Bhakti Siwi Desa Soran.

\section{SARAN}

1. Kepada orangtua untuk meningkatkan pengetahuan melalui berbagai cara atau media agar bisa memberikan stimulasi bahasa yang optimal kepada anaknya. 
2. Guru-guru TK senantiasa meningkatkan pengetahuan ibuibu melalui pendidikan kesehatan tentang stimulasi verbal pada anak usia dini pada saat pertemuan dengan orangtua/wali murid.

3. Ibu-ibu yang mempunyai anak usia dini diharapkan memperhatikan bahasa anak dan segera melakukan pembenaran pelafalan jika terjadi kesalahan pada anak sehingga koreksi yang dilakukan secara dini membantu anak untuk mengembangkan bahasanya dengan baik dan benar.

\section{DAFTAR PUSTAKA}

Budiman, A. dan Riyanto. 2013. Kapita Selekta Kuesioner: Pengetahuan dan Sikap dalam Penelitian Kesehatan. Salemba Medika, Jakarta.

Handayani, A., A. Samiasih dan Mariyam. 2013. "Hubungan Tingkat Pengetahuan Orang Tua Tentang Stimulasi Verbal dengan Perkembangan Bahasa Pada Anak Prasekolah di TK PGRI 116 Bangetayu Wetan", Jurnal Kesehatan:FIKKES. Volume 6. Semarang. Diunduh pada tanggal 6 Oktober 2016.

Hidayat, A. A. 2009. Metode Penelitian Keperawatan dan Teknik Analisis Data. Salemba Medika, Jakarta.
Santrock, J. W. 2007. Perkembangan Anak. Edisi XI. Erlangga, Jakarta.

Soetjiningsih. 2008. Tumbuh Kembang Anak . EGC, Jakarta.

Soetjiningsih dan I. G. N. G. Ranuh. 2014. Tumbuh Kembang Anak. Edisi II. EGC, Jakarta.

Susanto, A. 2014. Perkembangan Anak Usia Dini: Pengantar Dalam Berbagai Aspeknya. Prenadamedia Group, Jakarta.

Tembong, G. P. 2006. Smart Parenting. Elex Media Kompetindo, Jakarta.

Wawan, A dan Dewi, M. 2011. Teori dan Pengukuran Pengetahuan, Sikap, dan Perilaku Manusia. 2011. Nuha Medika, Yogyakarta.

Zubaedah, E. 2014. Pengembangan Bahasa Anak Usia Dini. Fakultas IImu Pendidikan Universitas Negeri Yogyakarta. Yogyakarta.

${ }^{1}$ Dosen Akper Panti Kosala

Surakarta

${ }^{2}$ Mahasiswa Akper Panti Kosala

Surakarta 